\title{
Effect on the Resistance of Concrete Acid Corrosion in Superficial Soil Layers
}

\author{
Jihong Wei $\mathbb{D}^{1},{ }^{1}$ Jin Liu $\left(\mathbb{D},{ }^{1}\right.$ Yuxia Bai, ${ }^{1}$ Zezhuo Song, ${ }^{1}$ Qiao Feng, ${ }^{1}$ Yi Lu, ${ }^{2}$ and Shaorui Sun $\mathbb{I D}^{1}$ \\ ${ }^{1}$ School of Earth Sciences and Engineering, Hohai University, Nanjing 210098, China \\ ${ }^{2}$ Key Laboratory of Earth Fissures Geological Disaster, Ministry of Land and Resource (Geological Survey of Jiangsu Province), \\ Jiangsu 210049, China
}

Correspondence should be addressed to Jin Liu; jinliu920@163.com

Received 17 April 2018; Accepted 25 September 2018; Published 15 October 2018

Guest Editor: Yongfeng Deng

Copyright (C) 2018 Jihong Wei et al. This is an open access article distributed under the Creative Commons Attribution License, which permits unrestricted use, distribution, and reproduction in any medium, provided the original work is properly cited.

\begin{abstract}
To understand the effect and mechanism of urban heat island (UHI) and the acid corrosion of concrete on the strength of concrete in superficial soil layers from Nanjing area, both laboratory and field tests of accelerated corrosion of concrete were carried out and analyzed. The laboratory test results indicate that the concrete corrosion depends on acid concentration, tested time, and also on the temperature. The maximum corrosion coefficient ( $K$-value) of $45.86 \%$, as observed at $10 \%$ of acid concentration, $40^{\circ} \mathrm{C}$ of tested temperature, and 90 days of tested time, was about 2 times that of specimens with $10 \%$ of acid concentration, $5^{\circ} \mathrm{C}$ tested temperature, and tested after 90 days. The field test showed that the compressive strength of specimens in urban station was lower than that of specimens in rural station. The $K$-value of specimens with same acid concentration observed at urban area was higher than that of specimens at rural area. Both the laboratory and field tests showed that the temperature has an increasingly powerful influence on the concrete corrosion under acid environment. Therefore, the UHI effect will accelerate the acid corrosion in concrete construction and may affect the stability and durability of buildings in urban areas. The safety and life assessment of concrete buildings therefore require great attention.
\end{abstract}

\section{Introduction}

Urban heat island (UHI) means that the temperature in urban areas is considerably higher than that in surrounding rural areas. It is becoming more and more significant in many major cities [1-3]. Recently, UHI effect and its corresponding environmental problems are increasing with the rapid development of worldwide urbanization $[4,5]$. The urban heat island intensity (UHII), which is the temperature difference between the urban area and the surrounding rural areas, was used to quantitatively describe the UHI effect [6]. It was demonstrated that the UHII in some major cities was as follows: $7.8^{\circ} \mathrm{C}$ in Mexico [7], $8.0^{\circ} \mathrm{C}$ in New York [8], $2.2^{\circ} \mathrm{C}$ in Alaska [9], 4.0 ${ }^{\circ} \mathrm{C}$ in Singapore [10], 7.4 $4^{\circ} \mathrm{C}$ in Shanghai [11], $3.3^{\circ} \mathrm{C}$ in Beijing [12], and $3.1^{\circ} \mathrm{C}$ in Nanjing [13]. Variation in temperature affects the engineering properties of soil in urban area, and consequently, the strength and stability of various engineered structures differ [14]. Many previous studies have shown that the increasing superficial soil temperature influenced the soil permeability, suction of unsaturated soils, and shear strength of soil [15-17].

Most of the buildings in urban and rural areas are made up of concrete. The durability of the concrete constructions is of great concern for the construction industry $[18,19]$. Among others, the acid corrosion is an important degradation process that affects the durability of concrete constructions [20-23]. Acid corrosion is the gradual destruction, or the wearing away, of materials by acidic compounds. The acids in superficial soil layers may come from the atmosphere, soil, or groundwater [24]. The concrete materials in the superficial soil layers are exposed to these acid environments whilst the temperature change will accelerate the acid corrosion of concrete construction [25-29]. Over the past century, many studies related to concrete deterioration in sulfate solution or chloride solution were widely conducted [30-32]. Tumidajski and Chan [33] proposed that the chloride penetration and diffusivity in the slag concrete increased the presence of sulfate ions. 
However, limited studies have paid attention to the effects of "heat island" on the acid corrosion of concrete construction in superficial soil layers $[13,14,34]$.

The main objective of this study is to evaluate the acid corrosion process of concrete in the superficial soil layers of urban area, which have higher ground temperature owing to the urban heat island effect. Laboratory and field tests of accelerated corrosion of concrete were carried out. The compressive strength properties of concrete specimens, cured at different temperatures $\left(5^{\circ} \mathrm{C}, 20^{\circ} \mathrm{C}\right.$, and $\left.40^{\circ} \mathrm{C}\right)$, different acid concentrations $(0 \%, 5 \%$, and $10 \%)$, and different tested times (30 days and 90 days), were studied by laboratory tests. The field contrast tests on the concrete specimens with three different concentrations of corrosion medium and different tested times were carried out in urban and rural observation stations. Finally, the mechanism of concrete acid corrosion and the urban heat island effect on the concrete strength of superficial soil layers in Nanjing area were analyzed.

\section{Materials and Test Methods}

2.1. Materials. In this study, sulfuric acid was selected as an aggressive medium for the test of accelerated acid attack. The different concentrations of sulfuric acid were prepared through dilution from concentrated sulfuric acid. A kind of quartz sand obtained from Nanjing city of China was used for this test. The range of particle size is $0.1 \sim 1 \mathrm{~mm}$, and the physical properties of sand are presented in Table 1. Ordinary Portland cement (OPC, Jiangsu Sincerity Cement Co. Ltd., Xuzhou, China) was selected, and its chemical compositions and the physical properties are shown in Table 2.

2.2. Test Methods. In order to understand the effect of urban heat island (UHI) on the resistance of mortar to acid attack in superficial soil layers, both laboratory and field tests of accelerated acid attack on cement mortar were carried out. The UHI effect was evaluated by the variation of compressive strength of concrete specimens tested in acid solution at different temperatures. The mortar with cement to sand ratio of 0.4 was prepared for tests. The moisture content and dry density of the prepared samples were $10 \%$ and $1.70 \mathrm{~g} / \mathrm{cm}^{3}$, respectively. The details of specimens for acid attack are given in Tables 3 and 4. Sand was mixed homogenously with cement powder, and then predetermined amount of water was added. After that, sample was casted into moulds of $50 \mathrm{~mm}$ diameter and $80 \mathrm{~mm}$ height to prepare cylindrical specimens. After demoulding, all the specimens were cured in cement maintenance box for 28 days.

Nine groups of the specimens were tested in the laboratory, and another six groups were used for field test. In the laboratory, three different temperatures $\left(5^{\circ} \mathrm{C}, 20^{\circ} \mathrm{C}\right.$ and $\left.40^{\circ} \mathrm{C}\right)$ and three different acid concentrations (0\%, 5\% and 10\%) were applied. Each group of specimens was placed in plastic box that was filled with acid solution; subsequently, every three groups of specimens with different acid concentrations were kept in a temperature cabinet with constant temperature for 30 and 90 days, respectively, and then the compressive strengths were tested.
In the field, two different locations built with long-term observation stations in Nanjing, China, were selected, as illustrated in Figure 1. The temperatures of underground soil $(0-300 \mathrm{~cm}$ depth) were recorded continuously. The urban observation station was located in an open yard near Hongshan Road, where the UHI was observed to be more specific [35]. The rural observation station is about $40 \mathrm{~km}$ away from the urban station, located in Gaomiao village, and generally surrounded by agricultural land. Three groups of specimens with three different concentrations of corrosion medium were placed in urban observation station, and the other three groups were placed in rural observation station. All the specimens were buried in superficial soil layers, and the schematic diagram of burial depth condition is shown in Figure 2. The compressive strength of each group of specimens was determined at 3 months, 6 months, 9 months, and 12 months. This field test was performed during April 1, 2011, to March 31, 2012. The compressive strength tests were carried out on June 30, September 30, and December 31 of the year 2011 and March 31, 2012.

The unconfined compressive strength (UCS) of sample after attack was determined in triplicate using a rock press apparatus, and the average value was used to calculate the coefficient of corrosion $(K)$ according to the formula as follows:

$$
K=\left[\frac{\left(R_{1}-R_{2}\right)}{R_{1}}\right] * 100 \% .
$$

where $K$ is defined as the corrosion index of concrete specimen and $R_{1}$ and $R_{2}$ are the UCS of the uncorroded and corroded concrete specimens under the same temperature condition.

\section{Test Results and Analyses}

3.1. Laboratory Test Results. UCS of specimens with different acid corrosion medium concentration, ambient temperature, and tested time are presented in Table 3. The variation of compressive strength of concrete specimens with temperature and acid concentration is shown in Figures 3 and 4. As can be seen in Figure 3, the compressive strengths of all specimens tested after 30 days and 90 days increase with increasing tested temperature. The tendency of uncorroded specimens is more significant than the other specimens with acid concentration of $5 \%$ and $10 \%$. As seen in Figure 4, the compressive strengths of specimens tested after 30 days and 90 days decreased with increasing concentration of acid medium. This tendency is more apparent at higher ambient temperature.

Corrosion coefficient $(K)$ of specimens tested after 30 and 90 days is presented in Table 3. The variation of $K$ with ambient temperature is illustrated in Figure 5. As seen, the $K$ value of specimens for both tested time 30 and 90 days increases with the increase in ambient temperature. The maximum $K$-value is observed to be $45.86 \%$ at $10 \%$ of acid corrosion concentration, $40^{\circ} \mathrm{C}$ of tested temperature, and 90 days of tested time, which is about 2 times that of specimen with $10 \%$ of acid concentration, $5^{\circ} \mathrm{C}$ of tested temperature, and 90 days of tested time. With the same acid concentration, 
TABle 1: Physical properties of sand.

\begin{tabular}{lcccccccc}
\hline Quality percentage of different size particles & $\begin{array}{c}\text { Constrained } \\
\text { grain size } \\
\left(D_{60}\right)\end{array}$ & $\begin{array}{c}\text { Intermediate } \\
\text { particle } \\
\text { diameter }\left(D_{30}\right)\end{array}$ & $\begin{array}{c}\text { Effective } \\
\text { size } \\
\left(D_{10}\right)\end{array}$ & $\begin{array}{c}\text { Uniformity } \\
\text { coefficient } \\
\left(C_{\mathrm{u}}\right)\end{array}$ & $\begin{array}{c}\text { Curvature } \\
\text { coefficient } \\
\left(C_{\mathrm{c}}\right)\end{array}$ & $\begin{array}{c}\text { Specific } \\
\text { gravity } \\
\left(G_{\mathrm{s}}\right)\end{array}$ \\
\hline $12 \%$ & $0.5 \sim 0.25(\mathrm{~mm})$ & $0.25 \sim 0.1(\mathrm{~mm})$ & 0.38 & 0.29 & 0.17 & 2.24 & 1.30 & 2.65 \\
\hline
\end{tabular}

TABLe 2: Chemical composition and physical properties of cement.

\begin{tabular}{ccccccccc}
\hline $\mathrm{SiO}_{2}$ & $\mathrm{Al}_{2} \mathrm{O}_{3}$ & $\mathrm{Fe}_{2} \mathrm{O}_{3}$ & $\mathrm{CaO}$ & $\mathrm{MgO}$ & $\mathrm{SO}_{3}$ & Others & Specific surface area & Compressive strength (standard curing) \\
\hline $20.3 \%$ & $4.3 \%$ & $3.5 \%$ & $62.4 \%$ & $2.8 \%$ & $3.3 \%$ & $1.6 \%$ & $387 \mathrm{~m}^{2} / \mathrm{kg}$ & $32.5 \mathrm{MPa}$ \\
\hline
\end{tabular}

TABLE 3: The compressive strengths of corrosion concrete with various temperatures.

\begin{tabular}{|c|c|c|c|c|c|c|c|}
\hline \multirow[t]{2}{*}{ Container number } & \multirow[t]{2}{*}{ Sample number } & \multirow[t]{2}{*}{ Temperature $\left({ }^{\circ} \mathrm{C}\right)$} & \multirow[t]{2}{*}{$\mathrm{SO}_{4}^{2-}(\%)$} & \multicolumn{2}{|c|}{$\begin{array}{l}\text { Compressive strength } \\
(\mathrm{MPa})\end{array}$} & \multicolumn{2}{|c|}{$\begin{array}{c}\text { Corrosion index } K \\
(\%)\end{array}$} \\
\hline & & & & 30 days & 90 days & 30 days & 90 days \\
\hline $\bar{L}-1$ & 6 & 5 & 0 & 23.73 & 26.34 & 0 & 0 \\
\hline $\mathrm{L}-2$ & 6 & 20 & 0 & 29.59 & 30.19 & 0 & 0 \\
\hline L-3 & 6 & 40 & 0 & 38.24 & 38.92 & 0 & 0 \\
\hline $\mathrm{L}-4$ & 6 & 5 & 5 & 20.07 & 21.89 & 15.42 & 16.89 \\
\hline L-5 & 6 & 20 & 5 & 22.91 & 21.87 & 22.57 & 27.56 \\
\hline L-6 & 6 & 40 & 5 & 28.84 & 23.66 & 24.58 & 39.20 \\
\hline $\mathrm{L}-7$ & 6 & 5 & 10 & 18.31 & 19.87 & 22.84 & 24.56 \\
\hline $\mathrm{L}-8$ & 6 & 20 & 10 & 20.32 & 20.12 & 31.33 & 33.35 \\
\hline L-9 & 6 & 40 & 10 & 20.95 & 21.07 & 45.21 & 45.86 \\
\hline
\end{tabular}

TABLE 4: The corrosion test results of concrete at urban and rural observation stations.

\begin{tabular}{|c|c|c|c|c|c|c|c|c|c|c|c|}
\hline \multirow{2}{*}{ Number } & \multirow{2}{*}{$\begin{array}{c}\text { Sample } \\
\text { numbers }\end{array}$} & \multirow{2}{*}{ Stations } & \multirow{2}{*}{$\mathrm{SO}_{4}^{2-}(\%)$} & \multicolumn{4}{|c|}{ Compressive strength $(\mathrm{MPa})$} & \multicolumn{4}{|c|}{ Corrosion index $K(\%)$} \\
\hline & & & & 3 months & 6 months & 9 months & 12 months & 3 months & 6 months & 9 months & 12 months \\
\hline F-1 & 12 & & 0 & 15.79 & 15.84 & 15.71 & 15.83 & 0 & 0 & 0 & 0 \\
\hline F-2 & 12 & Urban & 5 & 14.34 & 12.92 & 10.87 & 9.70 & 9.20 & 18.45 & 30.81 & 38.73 \\
\hline F-3 & 12 & & 10 & 12.32 & 9.86 & 7.85 & 6.81 & 21.96 & 37.75 & 50.00 & 56.95 \\
\hline F-4 & 12 & & 0 & 15.98 & 15.99 & 15.88 & 15.97 & 0 & 0 & 0 & 0 \\
\hline F-5 & 12 & Rural & 5 & 14.97 & 14.53 & 12.26 & 10.96 & 6.34 & 9.13 & 22.79 & 31.40 \\
\hline F-6 & 12 & & 10 & 14.16 & 11.99 & 10.25 & 9.45 & 11.40 & 25.00 & 35.48 & 40.83 \\
\hline
\end{tabular}

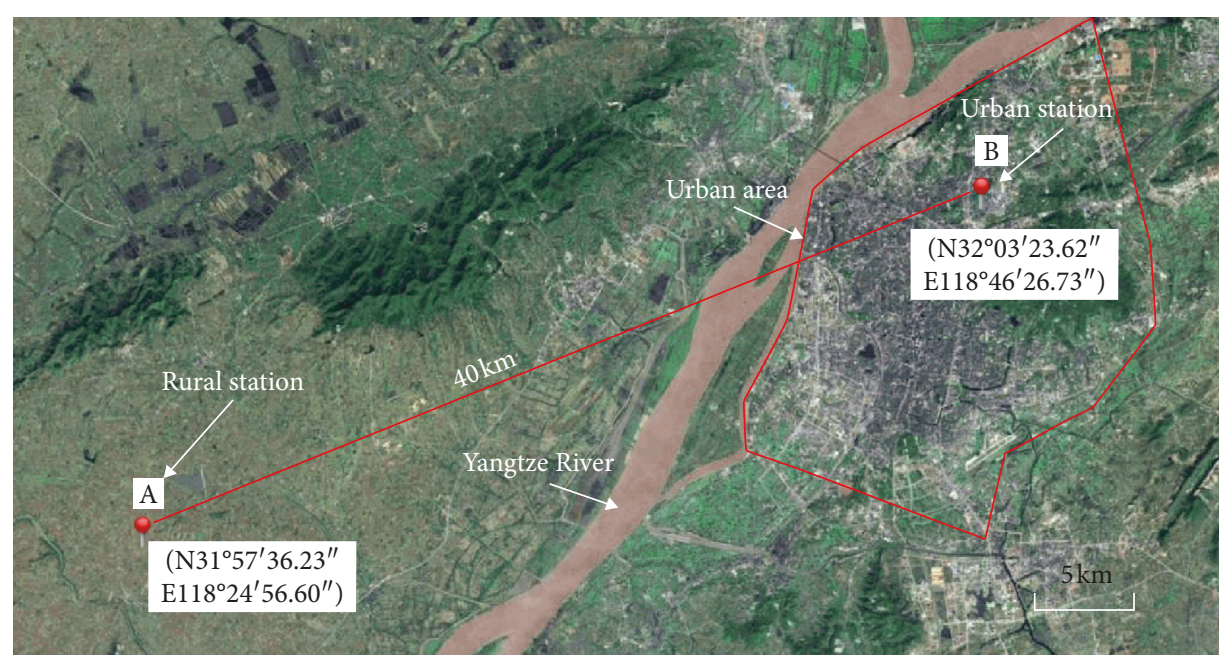

Figure 1: Locations of the urban and rural observation stations. 


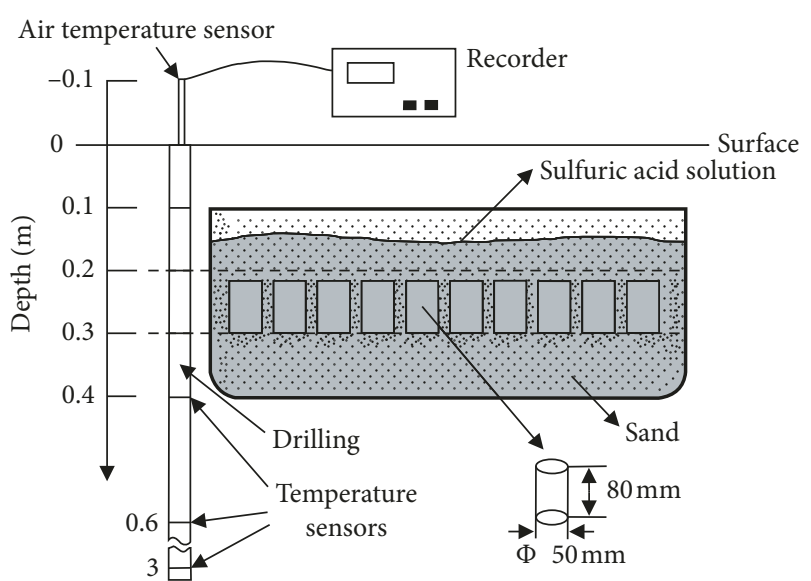

FIGURE 2: Schematic diagram of field test.



FIGURE 3: Variation of compressive strength of concrete specimens with temperature.

the $K$-value of specimens tested at tested time of 90 days is higher than that of specimens tested at tested time of 30 days. Compared with the $5 \%$ acid concentration, the specimens with $10 \%$ acid concentration have greater corrosion and higher $K$-value. With the acid concentration of $10 \%$ as an example, the $K$-value of specimen tested at 90 days with tested temperatures $5^{\circ} \mathrm{C}, 20^{\circ} \mathrm{C}$, and $40^{\circ} \mathrm{C}$ is $24.56 \%, 33.35 \%$, and $45.86 \%$, respectively.

It can be calculated from Table 3 that within $5^{\circ} \mathrm{C}$ to $40^{\circ} \mathrm{C}$, the corrosion index $K$-value of specimens tested after 90 days with the acid concentration of $5 \%$ and $10 \%$ increases about $0.64 \%$ and $0.61 \%$, respectively, while temperature rising every once.

3.2. Field Test Results. The compressive strength results of field test are presented in Table 4. It was found that UCS of specimens with the same acid concentration in urban station is lower than that of specimens in rural station. The

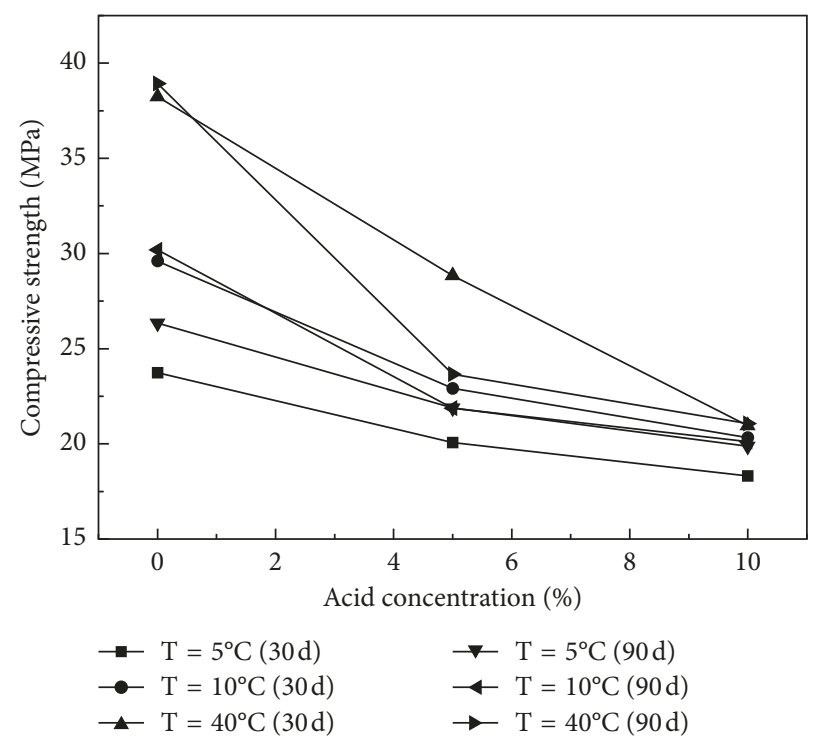

FIgURE 4: Variation of compressive strengths of concrete specimens with acid concentration.

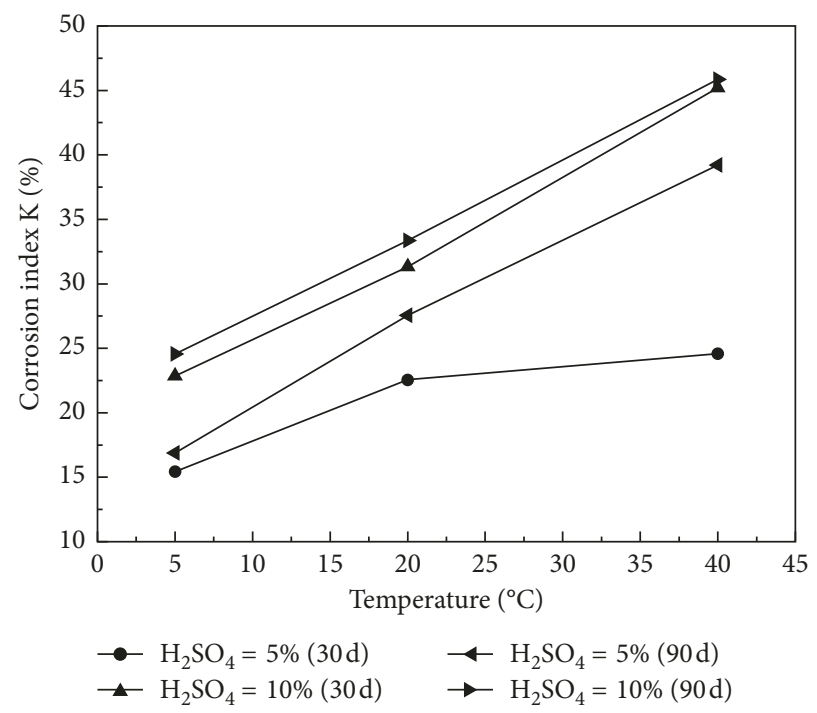

Figure 5: Variation of $K$-value with tested temperature.

compressive strengths of specimens at both urban as well as rural stations reduce as acid concentration increases. It also can be seen from Table 4 that the $K$-values of specimens with the same tested time increase with increasing acid concentration, and the specimens of urban area have stronger tendency. In addition, it is apparent that the corrosion coefficients ( $K$-value) of specimens with same acid concentration observed at urban area are higher than that of specimens at rural area. As observed with the acid concentration of $10 \%$ (Figure 6 ), the $K$-values of urban specimens at age of 3,6, 9, and 12 months are significantly higher than that of rural specimens. The $K$-value of specimens with the acid concentration $10 \%$ and tested time of 12 months at urban and rural area is $56.95 \%$ and $40.83 \%$, respectively. The $K$-value obtained at urban area is about 1.39 times than that of specimens tested at rural area. 




Figure 6: Corrosion index of urban and rural specimens.

The variation of corrosion index $K$-value with the tested time is illustrated in Figure 7. As observed, the corrosion index of both urban and rural specimens increases with the increase in the tested time. The increasing tendency of specimen with acid concentration of $10 \%$ is stronger than the specimen with acid concentration of $5 \%$. With the same acid concentration, the corrosion index of specimens at urban station is larger than that of specimens at rural station in the whole test process.

3.3. UHI Effect on Concrete Corrosion. The average monthly temperatures $\left(T_{\mathrm{m}}\right)$ from April 1, 2011, to March 31, 2012, were calculated for both urban $\left(T_{\mathrm{m}, \mathrm{u}}\right)$ and rural $\left(T_{\mathrm{m}, \mathrm{r}}\right)$ soils at different depths and are presented in Table 5. In this study, the range of depths $0-40 \mathrm{~cm}$ is considered to explore the UHI effect on concrete corrosion. The average monthly temperatures $\left(T_{\mathrm{m}}\right)$ for urban and rural soil during the depths of $0-40 \mathrm{~cm}$ calculated from Table 5 are shown in Figure 8. The maximum $T_{\mathrm{m}}$ is observed in August as $29.28^{\circ} \mathrm{C}$ in the urban area and $26.59^{\circ} \mathrm{C}$ in the rural area. The minimum $T_{\mathrm{m}}$ values of urban and rural areas as observed in February are $7.61^{\circ} \mathrm{C}$ and $4.55^{\circ} \mathrm{C}$, respectively. It can be seen from Figure 8 that the monthly temperatures of both urban and rural areas have a similar tendency of increase to the maximum value from April to August, and then the value begins to decrease and reaches the minimum value in February of the next year. At last, it rises to a higher value for the next monthly temperature cycle.

The urban heat island intensity (UHII) is defined as the temperature difference between the urban and surrounding rural locations. Based on this data, the differences of soil temperature at different time scales were calculated to examine the UHII patterns, such as monthly averages, 3-monthly averages, and yearly averages. The monthly, 3-monthly, and yearly UHII in the depth range of $0-40 \mathrm{~cm}$ is given in Table 5 . As observed, the maximum monthly UHII is observed in November as $3.67^{\circ} \mathrm{C}$, and the minimum monthly UHII is observed in July as $0.49^{\circ} \mathrm{C}$; the 3-monthly UHII in the tested time is $1.25^{\circ} \mathrm{C}, 1.91^{\circ} \mathrm{C}, 3.61^{\circ} \mathrm{C}$, and $3.26^{\circ} \mathrm{C}$, respectively; and the yearly UHII is $2.51^{\circ} \mathrm{C}$.

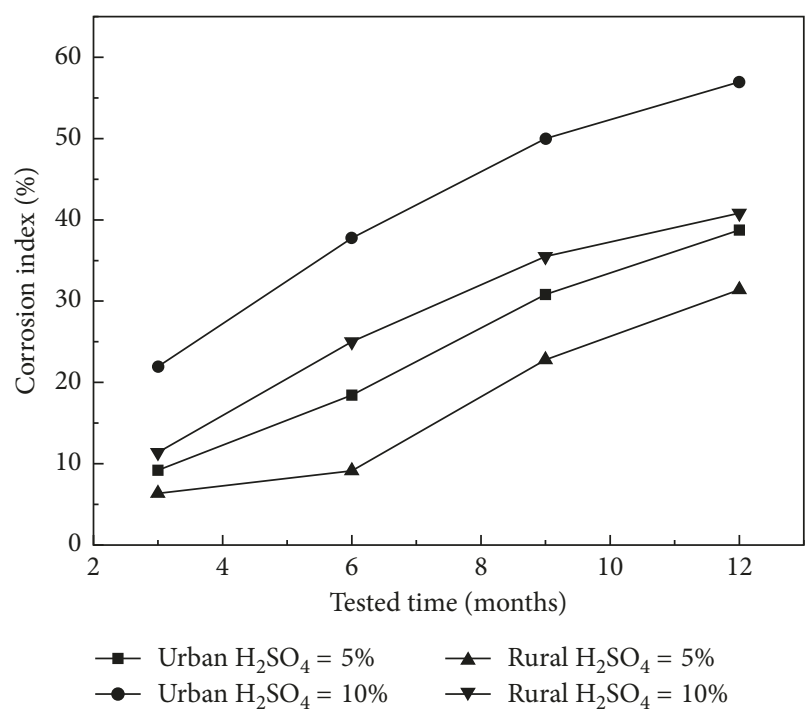

Figure 7: Variation of corrosion index $K$-value with the tested time.

The temperature corrosion effect (TCE) is defined as the rising range of the corrosion index $K$-value of concrete specimens with every temperature rise. The laboratory test results show that within $5^{\circ} \mathrm{C}$ to $40^{\circ} \mathrm{C}$, the TCE values of specimens with the acid concentration of $5 \%$ and $10 \%$ are about $0.64 \% /{ }^{\circ} \mathrm{C}$ and $0.61 \% /{ }^{\circ} \mathrm{C}$, respectively. The field test results show that the corrosion differences between the urban and rural locations at tested 3, 6, 9, and 12 months period are $2.86 \%, 9.32 \%, 8.02 \%$, and $7.33 \%$, respectively, for specimens with the acid concentration of $5 \%$ and are $10.56 \%$, $12.75 \%, 14.52 \%$, and $16.12 \%$, respectively, for specimens with the acid concentration of $10 \%$. The 3-, 6-, 9-, and 12monthly UHII is $1.25^{\circ} \mathrm{C}, 1.58^{\circ} \mathrm{C}, 2.26^{\circ} \mathrm{C}$, and $2.51^{\circ} \mathrm{C}$, respectively. Therefore, the TCE caused by UHII is $2.29 \% /{ }^{\circ} \mathrm{C}$, $5.90 \% /{ }^{\circ} \mathrm{C}, 3.55 \% /{ }^{\circ} \mathrm{C}$, and $2.92 \% /{ }^{\circ} \mathrm{C}$ for specimens with the acid concentration of $5 \%$ and are $8.45 \% /{ }^{\circ} \mathrm{C}, 8.07 \% /{ }^{\circ} \mathrm{C}$, $6.43 \% /{ }^{\circ} \mathrm{C}$, and $6.42 \% /{ }^{\circ} \mathrm{C}$ for specimens with the acid concentration of $10 \%$.

The above results obtained from both laboratory and field tests indicate that the temperature has an accelerated influence on the concrete corrosion under acid environment. Therefore, the urban heat island (UHI) will accelerate the acid corrosion of concrete construction and may affect the stability and durability of buildings in urban areas. The safety and life assessment of concrete buildings must require more attention.

\section{Mechanism Analysis}

Dissolution and decomposition are two kinds of concrete corrosion in acid medium. The dissolution type of corrosion is defined as the dissolution of composition of cement, such as calcium hydroxide being precipitated in the form of corrosion damage. Decomposable corrosion is defined as the chemical reaction between corrosive medium and cement hydrates. Usually, the decomposed corrosion occurs primarily on the surface layer of cement concrete, and its 


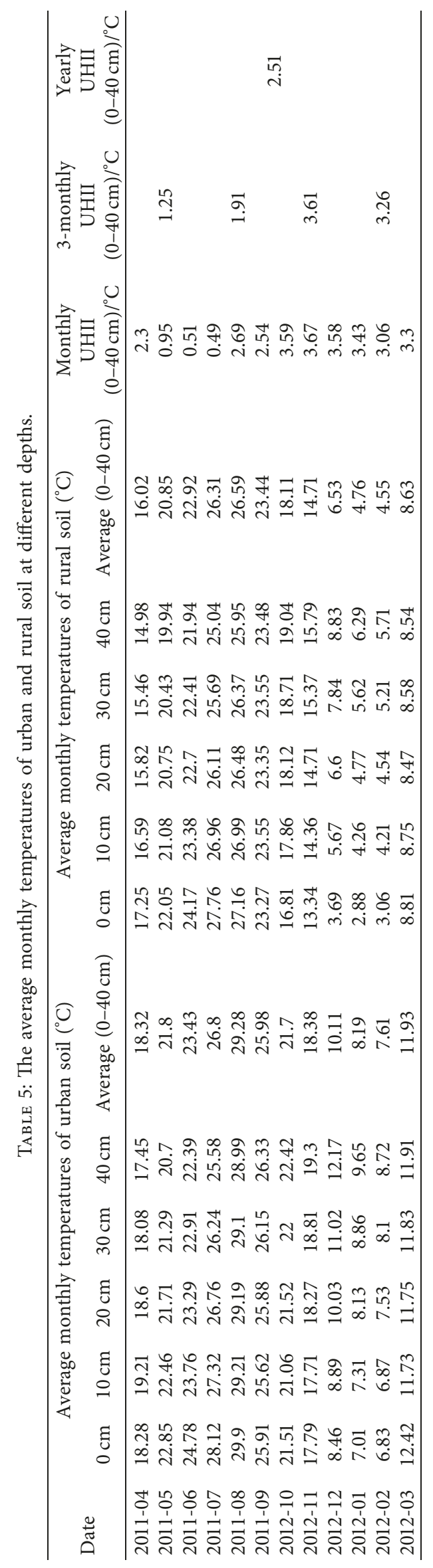




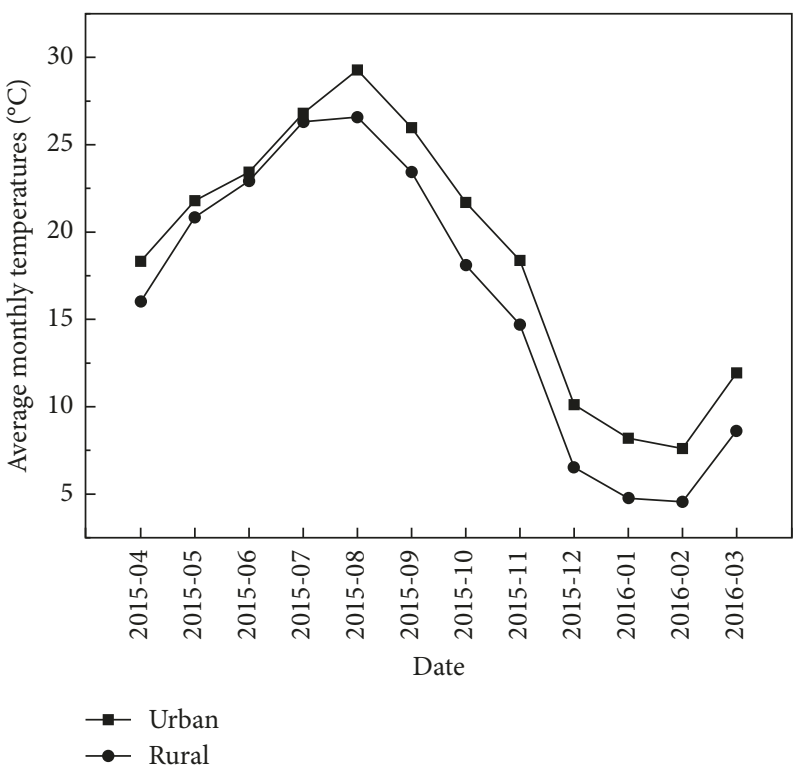

FIgURE 8: Average monthly temperatures for urban and rural soils in the depth ranges of $0-40 \mathrm{~cm}$.

internal structure remains intact. In this study, the failure mode of specimens indicates that the decomposed corrosion is the main form of the sulfuric acid corrosion of concrete specimens.

The variation in microstructure of concrete specimen was observed by scanning electron microscopy (SEM, SU3500, Hitachi) at an acceleration voltage of $5 \mathrm{kV}$ and a beam current of $100 \mu \mathrm{A}$. The specimen is fixed on the object stage and connected with the conductive silver paste. Subsequently, the specimen surface is sputtered with gold with a voltage of $700 \mathrm{~V}$ for a minute by the ion sputter (E1010, Hitachi). The photomicrographs of scanning electron microscope (SEM) of the concrete specimen with tested time of 6 months, acid concentration of 5\%, and buried in urban soil are shown in Figure 9. As seen, the internal structures of specimens still maintain intact (Figure 9(a)). The outer layer of cement hydration product is corroded (Figure 9(c)), and an obvious corrosion boundary is present between inner and outer layers (Figure 9(b)). As a consequence, the structure became loose, and the strength of the concrete specimen reduced.

The corrosion process is that the acid medium penetrates through the matrix of concrete specimen to react with $\mathrm{Ca}$ $(\mathrm{OH})_{2}$ and calcium silicate hydrate $(\mathrm{C}-\mathrm{S}-\mathrm{H})$ to form calcium salts. The reaction process is shown in the following chemical Equations (2) and (3).

$$
\begin{aligned}
\mathrm{Ca}(\mathrm{OH})_{2}+\mathrm{H}_{2} \mathrm{SO}_{4} & =\mathrm{CaSO}_{4}+2 \mathrm{H}_{2} \mathrm{O} \\
\mathrm{mCaO} \cdot \mathrm{nSiO}_{2} & +\mathrm{mH}_{2} \mathrm{SO}_{4}+\mathrm{H}_{2} \mathrm{O}=\mathrm{mCaSO}_{4}+\mathrm{nSi}(\mathrm{OH})_{4}
\end{aligned}
$$

This chemical reaction accelerates with the increasing sulfuric acid concentration and environment temperature. The increase of acid concentration or the temperature can induce the accelerated penetration rate of sulfuric acid into mortar sample, higher solubility, and activity of ions.
Therefore, the compressive strengths of concrete specimens reduce with the increasing acid concentration or the temperature in the tests.

The UHI effect in soil is actually equivalent to an additional temperature field in natural soil. The corrosion rate of the concrete materials in urban acid environment is accelerated due to UHI effect. These results have been demonstrated in the above field test.

\section{Conclusions}

A series of laboratory and field tests were performed to study urban heat island effect on the concrete acid corrosion. The effects of the acid concentration and environment temperature on the compressive strength and corrosion index of concrete specimens were investigated. The main conclusions from the present study can be summarized as follows:

(1) It is observed from laboratory testing that the concrete corrosion varies and depends on the acid concentration, tested time, and also on the temperature. The concrete corrosion index $K$-value increases with the increasing acid concentration, tested time, and ambient temperature. The maximum $K$ value of $45.86 \%$ is observed at $10 \%$ of acid concentration, $40^{\circ} \mathrm{C}$ of ambient temperature, and 90 days of tested time, which is about 2 times of that of specimens with $10 \%$ of acid, $5^{\circ} \mathrm{C}$ of temperature, and 90 days tested. Within $5^{\circ} \mathrm{C}$ to $40^{\circ} \mathrm{C}$, the corrosion index $K$-value of specimens tested after 90 days, with the acid concentration of $5 \%$ and $10 \%$, increases about $0.61 \%$ and $0.63 \%$, respectively, while temperature rising every once.

(2) The field test shows that the compressive strength of specimens in the urban station is lower than that of specimens in the rural station. The compressive strength of specimens at both urban and 


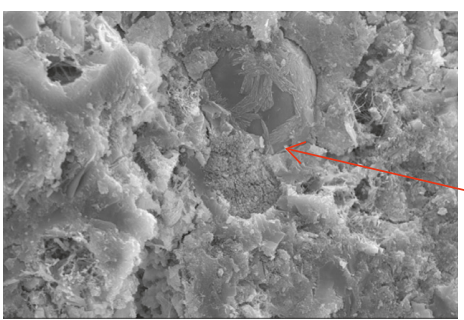

(a)

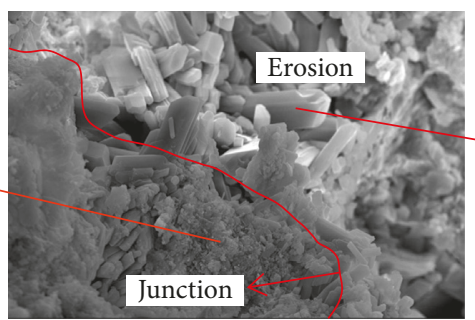

(b)

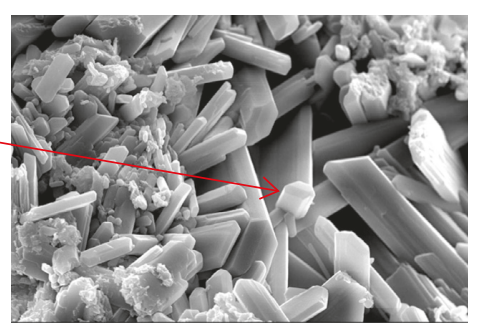

(c)

FIGURE 9: Photomicrographs of SEM of acid corrosion concrete specimen: (a) centre of the specimen with magnification 1500x; (b) junction of the specimen with magnification 1500x; (c) erosion of the specimen with magnification 2000x.

rural stations reduces with the increasing acid concentration. The $K$-values of specimens with some tested time increase with increasing acid concentration, and the specimens of urban area have stronger tendency. The corrosion coefficient $K$-value of specimens with same acid concentration observed at urban area is higher than that of specimens at rural area. The corrosion index of both urban and rural specimens increases with the increasing test time.

(3) SEM images indicate that the decomposed corrosion is a main form of the sulfuric acid corrosion of concrete specimens. The internal structure of specimens still maintains intact, the outer layer of cement hydration product is corroded, and an obvious corrosion boundary is observed between internal and outer layers. The structure becomes loose, and the strength of the concrete specimen may reduce.

(4) The soil profile temperature (within $40 \mathrm{~cm}$ depth) data during the period of April 1, 2011, to March 31, 2012, are obtained from two observation stations set up in urban and rural areas of Nanjing city, China. The maximum monthly UHII is observed in November as $3.67^{\circ} \mathrm{C}$, and the minimum monthly UHII is observed in July as $0.49^{\circ} \mathrm{C}$; the 3 -monthly UHII in the tested time is $1.25^{\circ} \mathrm{C}, 1.91^{\circ} \mathrm{C}, 3.61^{\circ} \mathrm{C}$ and $3.26^{\circ} \mathrm{C}$ respectively, and the yearly UHII is $2.51^{\circ} \mathrm{C}$. The corrosion differences between the urban and rural locations at tested 3, 6, 9, and 12 months period are $2.86 \%, 9.32 \%, 8.02 \%$, and $7.33 \%$, respectively, for specimens with the acid concentration of $5 \%$ and are $10.56 \%, 12.75 \%, 14.52 \%$ and $16.12 \%$, respectively, for specimens with the acid concentration of $10 \%$.

(5) Laboratory and field test results indicate that the temperature has an increasingly powerful influence on the concrete corrosion under acid environment. Therefore, the urban heat island (UHI) will accelerate the acid corrosion of concrete construction and may affect the stability and durability of buildings in urban areas. The safety and life assessment of concrete buildings must require great attention.

\section{Data Availability}

The data used to support the findings of this study are included within the article.

\section{Conflicts of Interest}

The authors declare that there are no conflicts of interest regarding the publication of this paper.

\section{Acknowledgments}

This research was financially supported by the Water Conservancy Science and Technology Project of Jiangsu Province, China (Grant no. 2017010), the National Natural Science Foundation of China (Grant no. 41472241), and the Fundamental Research Funds for the Central Universities (Grant no. 2016B05914). The authors gratefully acknowledge Dr. Bin Shi, Professor in the School of Earth Sciences and Engineering, Nanjing University, China, and Dr. Kai Gu, Associate Professor in the School of Earth Sciences and Engineering, Nanjing University, China, for their help and comments on this work.

\section{References}

[1] T. R. Oke, Boundary Layer Climate, Methuen, London, UK, 1987.

[2] H. S. Shang, Y. P. Song, and L. K. Qin, "Experimental study on strength and deformation of plain concrete under triaxial compression after freeze-thaw cycles," Building and Environment, vol. 43, no. 7, pp. 1197-1204, 2008.

[3] S. P. Huang, M. Taniguchi, M. Yamano, and C. H. Wang, "Detecting urbanization effects on surface and subsurface thermal environment-a case study of Osaka," Science of the Total Environment, vol. 407, no. 9, pp. 3142-3152, 2009.

[4] F. Al-Ajmi, D. L. Loveday, and V. I. Hanby, "The cooling potential of earth-air heat exchangers for domestic buildings in a desert climate," Building and Environment, vol. 41, no. 3, pp. 235-244, 2006.

[5] P. A. Mirzaei and F. Haghighat, "Approaches to study urban heat island-abilities and limitations," Building and Environment, vol. 45, no. 10, pp. 192-201, 2010.

[6] A. M. Rizwan, Y. C. L. Dennis, and C. H. Liu, "A review on the generation, determination and mitigation of Urban Heat Island," Journal of Environmental Sciences-China, vol. 20, no. 1, pp. 120-128, 2008.

[7] E. Jauregui, "Heat island development in Mexico City," Atmospheric Environment, vol. 31, no. 22, pp. 3821-3831, 1997.

[8] S. D. Gedzelman, S. Austin, R. Cermak et al., "Mesoscale aspects of the urban heat island around New York City," Theoretical and Applied Climatology, vol. 75, no. 1-2, pp. 29-42, 2003. 
[9] K. M. Hinkel, F. E. N. Nelson, A. E. Klene, and J. H. Bell, "The urban heat island in winter at barrow, Alaska," International Journal of Climatology, vol. 23, no. 15, pp. 1889-1905, 2003.

[10] N. H. Wong and C. Yu, "Study of green areas and urban heat island in a tropical city," Habitat International, vol. 29, no. 3, pp. 547-558, 2005.

[11] J. Shu, T. H. Jiang, and X. M. Yang, "Temporal characteristics of urban heat island in Shanghai," Shanghai Environmental Sciences, vol. 19, no. 11, pp. 532-534, 2000.

[12] J. H. Zhang, Y. Y. Hou, G. C. Li, H. Yan, L. M. Yang, and F. M. Yao, "The diurnal and seasonal characteristics of urban heat island variation in Beijing city and surrounding areas and impact factors based on remote sensing satellite data," Science in China Series D-Earth Sciences, vol. 48, no. S2, pp. 220-229, 2005.

[13] B. Shi, C. S. Tang, L. Gao, C. Liu, and B. J. Wang, "Observation and analysis of the urban heat island effect on soil in Nanjing, China," Environment Earth Sciences, vol. 67, no. 1, pp. 215229, 2012.

[14] C. Liu, B. Shi, C. S. Tang, and L. Gao, "A numerical and field Investigation of underground temperatures under urban heat island," Building and Environment, vol. 46, no. 5, pp. 12051210, 2011.

[15] D. Li and J. Fan, "A study of mechanical property of artificial frozen clay under dynamic load," Advances in Civil Engineering, vol. 2018, Article ID 5392641, 8 pages, 2018.

[16] H. Jansen, J. Carmeliet, and H. Hens, "The influence of soil moisture transfer on building heat loss via the ground," Building and Environment, vol. 39, no. 7, pp. 825-836, 2004.

[17] A. C. Jacinto, M. V. Villar, and R. Gomez-Espina, "Adaptation of the van Genuchten expression to the effects of temperature and density for compacted bentonites," Applied Clay Science, vol. 42, no. 3-4, pp. 575-582, 2009.

[18] R. V. Balendran and W. H. Martin-Buades, "The influence of high temperature curing on the compressive, tensile and flexural strength of pulverized fuel ash concrete," Building and Environment, vol. 35, no. 5, pp. 415-423, 2000.

[19] C. D. Atis and C. Bilim, "Wet and dry cured compressive strength of concrete containing ground granulated blastfurnace slag," Building and Environment, vol. 42, no. 8, pp. 3060-3065, 2007.

[20] M. Mohammed and C. L. Page, "Effect of temperature and salt contamination on carbonation of cements," Journal of Materials in Civil Engineering, vol. 8, no. 2, pp. 63-69, 1996.

[21] O. S. B. Al-Amoudi, M. Maslehuddin, A. N. Lashari, and A. A. Almusallam, "Effectiveness of corrosion inhibitors in contaminated concrete," Cement and Concrete Composites, vol. 25, no. 4-5, pp. 439-449, 2003.

[22] S. Aydın, H. Yazıcı, H. Yigiter, and B. Baradan, "Sulfuric acid resistance of high-volume fly ash concrete," Building and Environment, vol. 42, no. 2, pp. 717-721, 2007.

[23] J. O. Okeniyi, A. P. I. Popoola, C. A. Loto, O. A. Omotosho, S. O. Okpala, and I. J. Ambrose, "Effect of $\mathrm{NaNO}_{2}$ and $\mathrm{C}_{6} \mathrm{H}_{15} \mathrm{NO}_{3}$ synergistic admixtures on steel-rebar corrosion in concrete immersed in aggressive environments," Advances in Materials Science and Engineering, vol. 2015, Article ID 540395, 11 pages, 2015.

[24] M. Laura and M. H. Carolyn, "Influence of cation on Corrosion behavior of reinforcing steel in high-pH sulfate solutions," ACI Materials Journal, vol. 102, no. 4, pp. 279-286, 2005.

[25] X. S. Wang, B. S. Wu, and Q. Y. Wang, "Online SEM investigation of microcrack characteristics of concretes at various temperatures," Cement and Concrete Research, vol. 35, no. 7, pp. 1385-1390, 2005.

[26] M. J. Terro, "Properties of concrete made with recycled crushed glassat elevated temperatures," Building and Environment, vol. 41, no. 5, pp. 633-639, 2006.

[27] Y. B. Jiao, H. B. Liu, X. Q. Wang, Y. W. Zhang, G. B. Luo, and Y. F. Gong, "Temperature effect on mechanical properties and damage identification of concrete structure," Advances in Materials Science and Engineering, vol. 2014, Article ID 191360, 10 pages, 2014.

[28] S. M. Chang, S. K Oh, D. S. Seo, and S. M. Choi, "Characteristics of humidity-temperature changing in the belowgrade concrete structure by applying waterproofing materials on the exterior wall," Advances in Materials Science and Engineering, vol. 2015, Article ID 959502, 10 pages, 2015.

[29] K. C. He, R. X. Guo, Q. M. Ma, F. Yan, Z. W. Lin, and Y. L. Sun, "Experimental research on high temperature resistance of modified lightweight concrete after exposure to elevated temperatures," Advances in Materials Science and Engineering, vol. 2016, Article ID 5972570, 6 pages, 2016.

[30] L. X. Liu, "Brief Introduction on the study of erosion and prevention of concrete in Salt Lake and saline soil area of Chaerhan, Chaidamu," Journalof Building Materials, vol. 4, no. 4, pp. 395-400, 2001

[31] M. S. Menashi, D. Cohen, and J. Olek, "Mechanism of sulfate attack: a fresh look part 1 . Summary of experimental results," Cement and Concrete Research, vol. 32, no. 6, pp. 915-921, 2002.

[32] C. Argiz, M. Á. Sanjuán, P. Castro, and E. Álvarez, "Modeling of corrosion rate and resistivity of steel reinforcement of calcium aluminate cement mortar," Advances in Civil Engineering, vol. 2018, Article ID 1096282, 9 pages, 2018.

[33] P. J. Tumidajski and G. W. Chan, "Effect of sulfate and carbon dioxide on chloride diffusivity," Cement and Concrete Research, vol. 26, no. 4, pp. 551-556, 1996.

[34] A. M. Tang and Y. J. Cui, "Controlling suction by the vapour equilibrium technique at different temperatures and its application in determining the water retention properties of MX80 clay," Canadian Geotechnical Journal, vol. 42, no. 1, pp. 287-296, 2005.

[35] Y. Yang, W. Su, and N. Jiang, "Time-space character analysis of urban heat island effect in Nanjing city using remote sensing," Remote Sensing Technology and Application, vol. 21, no. 6, pp. 488-492, 2006. 


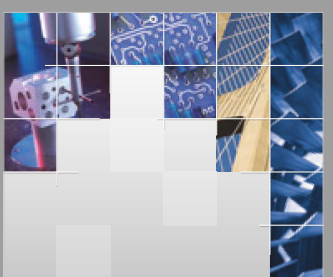

\section{Enfincering}
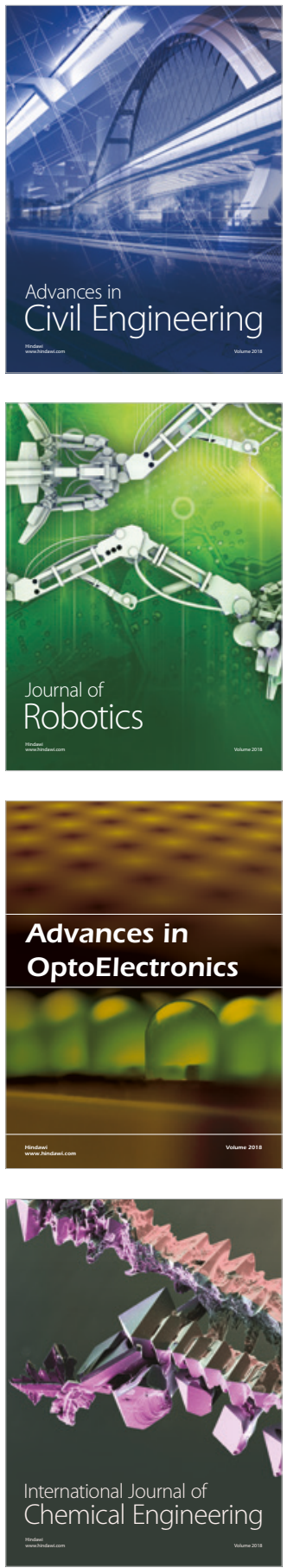

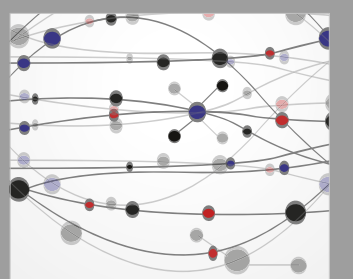

\section{Rotating \\ Machinery}

The Scientific World Journal

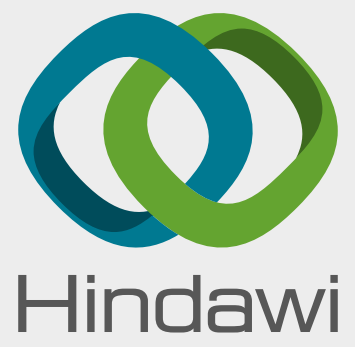

Submit your manuscripts at

www.hindawi.com
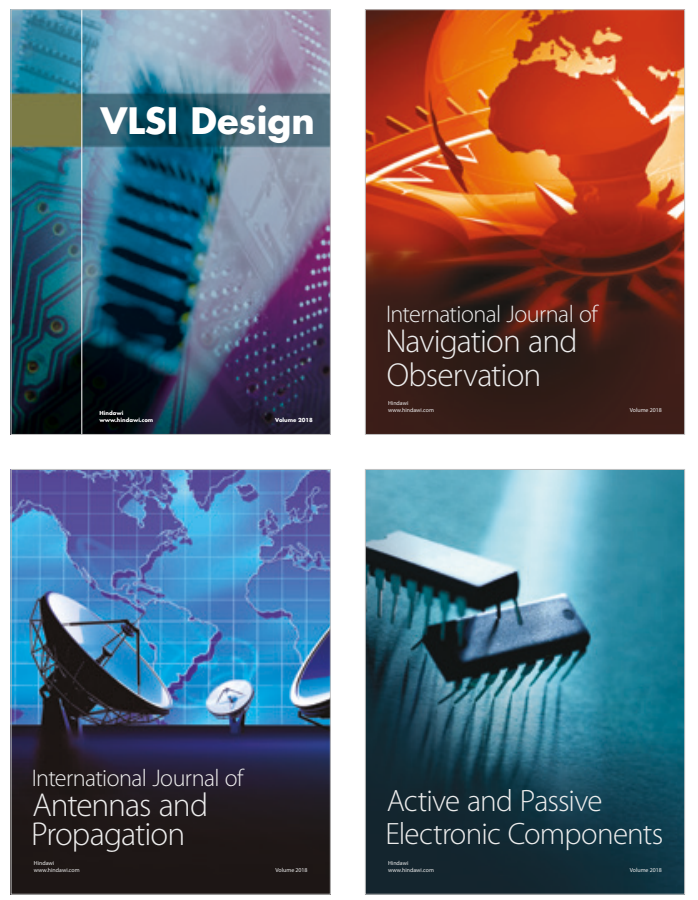


\section{Advances \\ Multimedia}
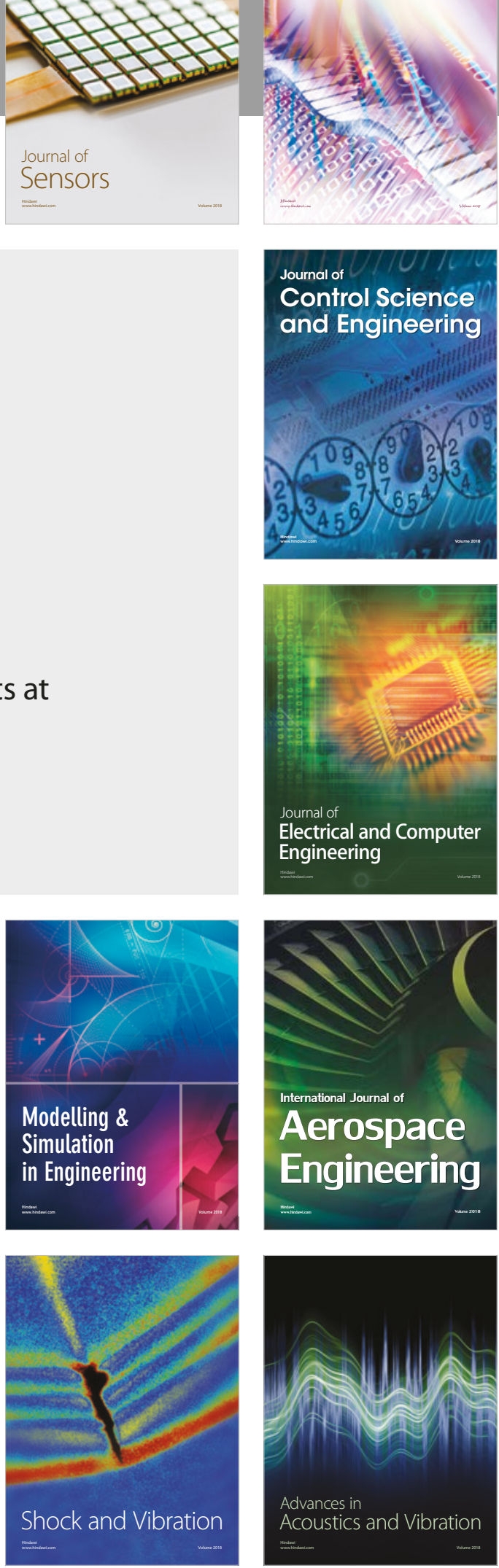